\title{
Multiple Simultaneos Metastases of Malignant Melanoma in the Stomach, Small and Large Intestine
}

Filip Vukmirovic ${ }^{1}$, Mihailo Vukmirovic ${ }^{2}$, Irena Vukmirovic ${ }^{2}$

${ }^{1}$ Clinical Center of Montenegro - Department of Pathology, Ljubljanska bb , Podgorica 81000, Montenegro; ${ }^{2}$ Clinical Center of Montenegro, Podgorica, Montenegro

Citation: Vukmirovic F, Vukmirovic M, Vukmirovic I. Multiple Simultaneos Metastases of Malignant Melanoma in the Stomach, Small and Large Intestine. Maced JMed Sci. 2013 Mar 15:6(1):5658. http://dx doi.org/10.3889/MJMS.18575773.2012.0269

Key words: melanoma; simultaneous metastases; stomach; small intestine; large intestine.

Correspondence: Dr. Filip Vukmirovic. Clinical Center of Montenegro, Department of Pathology, 81000, Montenegro. E-Mail: fvukmirovic@yahoo.com

Received: 21-Aug-2012; Revised: 05-Nov-2012 Accepted: 14-Nov-2012; Online first: 27-Nov-2012

Copyright: $\odot 2012$ Vukmirovic F. This is an openaccess article distributed under the terms of the Creative Commons Attribution License, which permits unrestricted use distribution, and reproduction in any medium, provided the original author and source are credited.

Competing Interests: The author have declared that no competing interests exist.

\section{Abstract}

Introduction: Melanoma is the primary tumor of melanocytes with gastrointestinal metastases which ocurs in about $2 \%$ of the patients.

Aim: The aim of this paper is to present a patient with multiple simultaneos metastases of melanoma in the gastrointestinal tract and draw attention to the occurrence of gastrointestinal symptoms in patients with melanoma.

Patients and Methods. We report a case of 74 years-old male with previously removed skin melanoma three years ago, and with symptoms such as anemia, weight loss and abdominal pain.

Results: On gastroscopy two tumours sized $3 \mathrm{~cm}$ and $3,5 \mathrm{~cm}$, on the front and rear stomach wall was detected. On colonoscopy, tumor size $3 \mathrm{~cm}$ was detected in sigmoid colon. During surgical operation in addition to these were found three more tumors on small intestine sized from $3 \mathrm{~cm}$ to $6 \mathrm{~cm}$. Microscopicaly the diagnosis of metastatic melanoma was made.

Conclusion: Gastrointestinal metastases of malignant melanoma are rare but it should be considered in any patient with a history of melanoma who develops gastrointestinal symptoms.

\section{Introduction}

Melanoma is malignant tumor of melanocytes and except in the skin, where it usually occurs as a primary tumor, it may occur in the oral, esophageal and anal mucosa of the gastrointestinal tract and eyes. As a tumor of high malignancy, it early gives lymphogenous and hematogenous metastasis. Gastrointestinal metastases of the melanoma were discovered in about $2 \%$ of the patients $[1,2]$. The symptom are nonspecific and include intestinal occlusion, bleeding from gastrointestinal tract, anemia, signs of acute abdomen and perforation of the intestine. The aim of this paper is to present a patient with multiple metastases of melanoma in the gastrointestinal tract and draw attention to the occurrence of gastrointestinal symptoms in patients with melanoma.

\section{Case report}

We report a case of 74 years-old male with 
previously removed skin melanoma three years ago. The tumor was nodular melanoma, Clark level IV. The patient was three years after the surgery without symptoms and relapse of disease, and then they was experiencing the symptoms such as anemia, weight loss and abdominal pain. Because the symptoms by gastrointestinal tract patients was underwent on gastroscopy and colonoscopy.

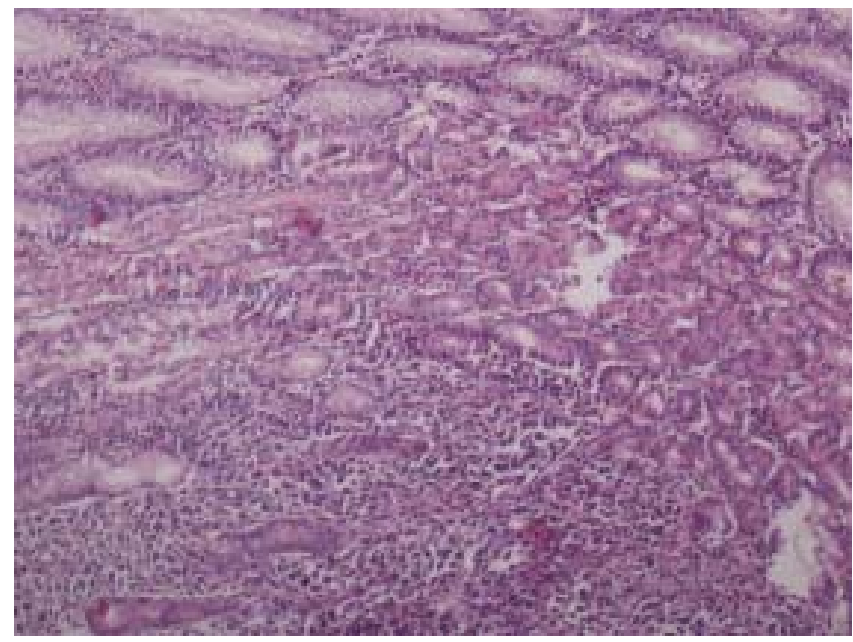

Figure 1: Melanoma tissue (down) in gastric mucosa (above) (HEx100).

On gastroscopy, two tumours sized $3 \mathrm{~cm}$ and $3.5 \mathrm{~cm}$, on the front and rear stomach wall were detected. The tumors were egsophitic apperance, gray-brown color. On colonoscopy, egsophitic brown tumor size 3 $\mathrm{cm}$ was detected in sigmoid colon. On preoperative CT scan the patients havent lung or liver metastases.

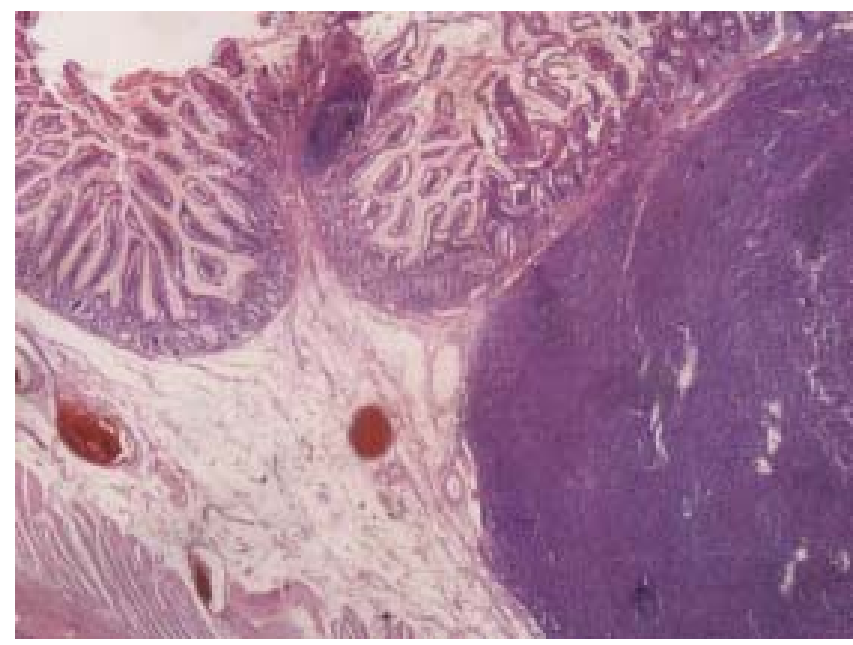

Figure 2: Tumor tissue with atypical spindlle cells (right) in small bowel (left). Small bowel metastasis of melanoma (HEx20).

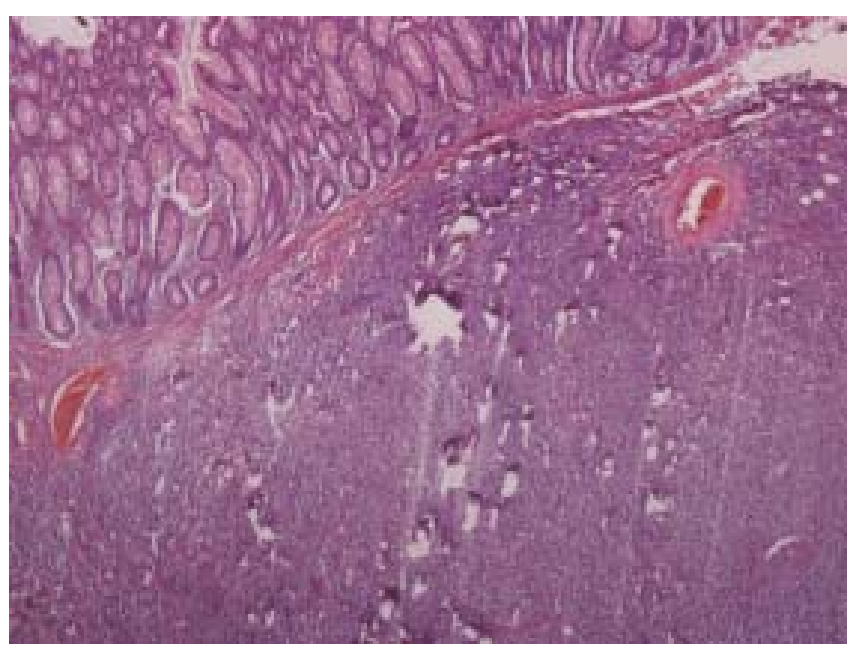

Figure 3: Tumor tissue in colonic submucosa. Melanoma metastaticum colon (HEX40).

During surgical operation in addition to these were found three more tumors on small intestine sized from $3 \mathrm{~cm}$ to $6 \mathrm{~cm}$. Partial gastrectomia and partial resections of the small and large bowel were made.

Macroscopically, we had gastric resection lenght $14 \mathrm{~cm}$ with two separated tumors size $3 \mathrm{~cm}$ and $3,5 \mathrm{~cm}$, two parts of small intestine lenght $25 \mathrm{~cm}$ and $27 \mathrm{~cm}$ with three separated tumors size $3 \mathrm{~cm}, 4 \mathrm{~cm}$ and $6 \mathrm{~cm}$, and parts of large bovel lenght $14 \mathrm{~cm}$ with tumor size $3 \mathrm{~cm}$. All tumors were brown color with infiltrative pattern.

Microscopically, all tumors were constituated of pleomorphic spindle and ovoid cell with hyperhromatic nuclei and prominent nucleoli (Fig.1-3). Mitoses were numerous with many atypical form. In some tumors cells

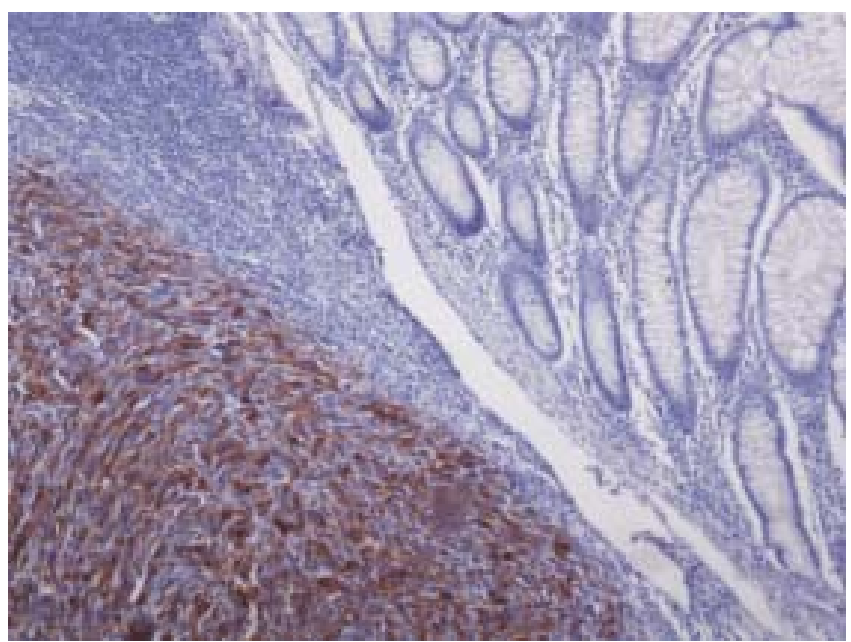

Figure 4: Tumors cells positivity on immunohistochemical HMB45 stain (HMB45X100). 
were melanin in cytoplasm. Tumors cells were positive for HMB45 (Fig. 4), Vimentin and S100, and negative for CK, EMA, LCA, Desmin, Actin, CD34 and CD117. Based on the above, the diagnosis of metastatic melanoma was made. After surgery, the patient recovered well and after 6 months of operation there were no signs of relapse.

\section{Discusion}

The most common site of metastasis of melanoma gastrointestinal tract described in literature is the small intestine [1-8]. In our case, unlike other, we described simultaneous metastasis of melanoma in the stomach, small and large intestine. The time from primary surgery to the occurrence of intestinal melanoma metastases varies, and metastasis can occur more years after diagnosis of primary tumor. In the literature, we found that the metastases may occurred 72 months after surgery of primary skin melanoma [5]. The data on the occurrence of intestinal metastases even after several years of operation of the primary melanoma are important for closely monitoring these patients. The treatment of choice in patients with intestinal melanoma metastases is surgical resections [4-7]. This method can be palliative and can also enable longer survival (9). The literature describes multi-year survival of patients in which achieve a complete surgical resection intestinal melanoma metastases, and prognosis in these patients is better than in patients with metastases melanoma in other organs [5, 7]. Caputy et al. were describe that patients with small bowel metastases had worse prognosis than patients with metastases in other part of gastrointestinal tract

Conclusion: Although gastrointestinal metastases of malignant melanoma are rare it should be considered in any patient with a history of melanoma who develops gastrointestinal symptoms and such patients should be examined through endoscopy. Surgical resection of metastases is the treatment of choice in these patients and can provide a longer survival.

\section{References}

1. Tsilimparis N, Menenakos C, Rogalla P, Braumann C, Hartmann J. Malignant melanoma metastasis as a cause of small-bowel perforation. Onkologie. 2009;32(6):356-8.

2. Petrovic M, Popovic M et al. Metastasis of malignant melanoma in the small intestine-case report. Acta Chir lugosl. 2000;47(1-2):97-101.

3. Butte JM, Meneses M, Waugh E, Parada H, De La Fuente $\mathrm{H}$. Ileal intussusception secondary to small bowel metastases from melanoma. Am J Surg. 2009;198(1):1-2.

4. Huang $\mathrm{YJ}, \mathrm{Wu} \mathrm{MH}$, Lin MT. Multiple small-bowel intussusceptions caused by metastatic malignant melanoma. Am J Surg. 2008;196(3):1-2.

5. Nemec L, Fait V, Silák J. Gastrointestinal metastases of malignant melanoma. Rozhl Chir. 2010;89(10):594-8.

6. Kolodziejski L, Lobaziewicz W, Wysocki W. [Metastases of the melanoma to the intestine]. Wiad Lek. 2006;59(11-12):7849.

7. Hao XS, Li Q, Chen H. Small bowel metastases of malignant melanoma: palliative effect of surgical resection. Jpn J Clin Oncol. 1999;29(9):442-4.

8. Fajdic J, Durovic D et al. lleus caused by metastasis of cutaneous malignant melanoma: case report. Acta Med Croatica. 2011;65(3):279-83.

9. Caputy GG, Donohue JH, Goellner JR, Weaver AL. Metastatic melanoma of the Gastrointestinal Tract: Results of Surgical Management. Arch Surg. 1991;126(11):1353-58. 